International Journal of Social Science and Economic Research

ISSN: 2455-8834

Volume:06, Issue:01 "January 2021"

\title{
THE ROLE OF MANAGEMENT INFORMATION SYSTEM (MIS) TO IMPROVE FUNCTIONS OF THE HUMAN RESOURCES MANAGEMENT
}

\author{
Dr. Nezar Mohammed Al-Samhi ${ }^{1}$ and Mr. Mugeeb Mohamed Mohamed Al-Samhi ${ }^{2}$ \\ ${ }^{1}$ Assistant Professor Dep- of IB, LIU Sana'a, Yemen. \\ ${ }^{2}$ College of Economics and Management, Nanjing University of Aeronautics and Astronautics, Nanjing \\ 210016, China
}

DOI: 10.46609/IJSSER.2021.v06i01.004 URL: https://doi.org/10.46609/IJSSER.2021.v06i01.004

\begin{abstract}
This study aimed to measure the role of the Management Information System (MIS) to improve functions of the human resources management: (recruitment, selection, appointment, training, and performance evaluation). The study found that most employees are aware of the importance of using (MIS) in the performance of human resources management, and that the use of (MIS) in human resource management (HRM) which means that there is no real difference between the attitudes of workers towards the use of the information systems (MIS) in the actual practices of the main activities of (HRM): (recruitment, selection, appointment, training, and performance evaluation) This paper serves as an introduction to this special issue on Management Information System (MIS) to improve functions of the human resources management and strategic ability and human resource management. The paper starts with a summary review of the current state of the human resource management strategic ability.
\end{abstract}

Keyword: (MIS): management information systems (HRM): human resource management.

\section{INTRODUCTION}

The business world has faced rapid changes and major challenges for the recent years, in which sciences have intertwined to be so related and interdependent body, that informatics, the tremendous progress in information and communication systems, the spread of the global communications network, the Internet and its numerous changes and rapid developments have a great impact on the performance of the work of organizations and their goals achievements. These things have caused a fundamental and fundamental change in the methods of implementing their activities and operations, which required the efforts of researchers and theorists. These complex environmental variables become targets of the organizations, which are looking for such things to gain more efficiency and effectiveness, in thinking carefully and searching for new and developed methods and strategies to control them. Recently, business organizations faced many environmental changes in various economic, social, political and cultural aspects, in addition to the tremendous scientific progress in the means of communication, information and 
International Journal of Social Science and Economic Research

ISSN: 2455-8834

Volume:06, Issue:01 "January 2021"

successive technological developments (Abdel Nabi, 2013).

As there is a role for (MIS) in the functions of human resources management, however, it did not receive the attention of researchers. And the main question for the professionals about the role of (MIS) in (HRM) remains unclear in regard to reach the desired efficiency and effectiveness from practicing jobs, and thus this reflects generally on the organization. And from this framework the issue in this study was identified.

Consequently, in light of the foregoing, this research in this field represents an urgent necessity to investigate and analyze the impact of contemporary challenges facing the human resources management (HRM).

\section{Previous studies:}

There are many Arabic and foreign studies and research related to the subject of this study. In this part, the researcher will shed light on recent studies and the most important aspects that those studies focused on in terms of their goals and results as well as what distinguishes this study from other studies:

\section{First: The Arabic studies:}

* The study of (Al-Sayes, 2019) aimed to identify the impact of management information systems (MIS) on the organizational performance in Hodeidah port represented in the dimensions of (MIS): (hardware - human - software - organizational), the obstacles and the benefits.

The samples of the study consisted of (129) employees, and the questionnaire from (30) items representing the study variables was distributed to them.

The most important results of the study were the positive moral effect of the dimensions of (MIS) in organizational performance which is not affected by the demographic characteristics of these sample individuals (employees).

* The study of (Said, 2019) aimed to determine the impact of the effectiveness of (MIS) on the crisis management in the food industry companies in Hodeidah Governorate, and to determine the impact of the end-user in the crisis management and the size of the use of this system (dimensions) in the crisis management.

The study samples were made up of (5) Food industry companies and the number of the sample individuals is (152). A questionnaire from (56) paragraphs representing the study variables was distributed.

The most important results were the availability of the dimensions of the effectiveness of (MIS) and the crisis management, in varying degrees in favor of the independent variable, as well as the 
International Journal of Social Science and Economic Research

ISSN: 2455-8834

Volume:06, Issue:01 "January 2021"

availability of impact between the dependent and independent variable by $56 \%$.

* The study of (Al-Khaled, 2018) aimed to know to which extent the awareness of private schools in the capital, Sana'a, is about the importance of the available (MIS) to improve the total performance of the private schools, as well as to define the basic requirements for (MIS), the obstacles and difficulties of its implementation in the administrative units (the objective of study),

The study samples consisted of (11) educational areas and (92) private schools. The distributed questionnaire consisted of (62) items to the study variables.

The most important results were reflected in the high awareness of the sample individuals about the importance of (MIS) and its contribution to improve the performance of administrative units, as well as the awareness that there are obstacles facing its implementation realizing the benefits of its implementations.

* The study of (Dabr, 2018) aimed to reveal the role of (MIS) in making decisions and solving problems in the industrial sector in Yemen by implementing it in (Dirham Industries Limited Company, in Hodeidah), and to know the ability level of the electronic infrastructure to apply (MIS) and the obstacles to its implementation.

The questionnaire of (61) items were distributed to (65) Dirham Company's managers and employees (the objective of study).

The most important results were that the decision-making and problem- solving process attracts the company's management, and that the obstacles and problems of using dimensions and requirements of (MIS) were decreased.

* The study of (Talabani, 2017) aimed to know the effect of information system in achieving organizational performance in the University of Babylon (the objective of the study) as well as to indicate the existence of obstacles of using the information system in the administrative units in the Babylon University.

The study population may consist (as a comprehensive count) of all employees at the different administrative levels of the university (50) individuals. A questionnaire from (61) paragraphs was distributed and a personal interview was conducted.

The most important results were that there is a discrepancy between the sample individuals of the study in the impact of the dimensions of information system and its infrastructure, and the support of higher management in facilitating these dimensions. The results also indicate that the most important variable is dimension of the human resources that causes the decrease of the use of information system in the university (objective of the study.) 


\section{International Journal of Social Science and Economic Research}

ISSN: $2455-8834$

Volume:06, Issue:01 "January 2021"

* The study of (Iskandar, 2011) addressed the importance of using information system and its effect in developing the performance of governmental organizations, as it aimed to determine the impact of the use of information system on developing the performance of the Central Organization for Control and Audition (COCA) in Yemen, and to identify the problems and obstacles that restrain the effectiveness of its use, and to deliver suggestions to improve this aspect.

The most important results of this study are to show the lack of full awareness among the leaders and employees about the importance of (IT), as well as limiting the use of information system in regular duties, indicating that there is no accurate system for measuring and evaluating information system systems in the Central Organization (the objective of the study).

* The study of (Ghuraibah, 2013) focused on measuring workers attitudes about the effectiveness of practicing the functions of the human resource management in the Saudi: Bin Laden Foundation in facing the challenges of globalization and its impact and dimensions on the effectiveness of human resources policies.

The most important results concluded in the study are: the necessity of raising the awareness among leaders about the importance of human resources management and its role in improving the foundation's performance by participating in global conferences and events, and enabling those in charge of human resources management to prepare strategic plans for the foundation, as well as re-describing jobs in the whole foundation and the specifications and qualifications that must be met by whoever occupies it.

\section{Second: The Foreign studies:}

* The study of (Yassin, 2017) has aimed at the fact of using management information system (MIS) in administrative decision making in the township of Irbid, and aimed to discover its role in the effectiveness of the administrative decision and the benefits and obstacles of its use. The study used the descriptive analytical approach in highlighting the dimensions and horizons of (MIS) and its role in decision-making.

For this study, (230) individuals as study sample were interviewed to get data.

The most important results of this study were that (MIS) has medium to high effective role, as well as its role in providing the required information to help in decision-making has effectiveness from medium to high.

* The study of (Khan \& Awan, 2017) has aimed to know the effect of (MIS) on organizations management knowing whether it give a positive impact on the performance of organizations (the study's objectives).

Therefore, the study used the descriptive analytical approach conducting interviews with 


\section{International Journal of Social Science and Economic Research}

ISSN: $2455-8834$

Volume:06, Issue:01 "January 2021"

individuals and distributing questionnaire in some organizations in the private sectors, in the Pakistani capital.

The study reached a number of results, the most important of which is that (MIS) is very important to enhance the performance of organizations and helps management higher-ups in setting goals and strategic plans and developing business plans and decision-making process with high efficiency.

* The study of (Adewoye \& Obasan, 2012) aimed to analyze the impact of information system on human resources management (HRM) in the American electronic industries sector (the objective of the study), and to know the attitudes of workers according to their demographic characteristics and to know the extent of resistance to change and the difficulties that (HRM) encounters.

For this study, the descriptive analytical approach is used by questionnaires to get information related to the study variables.

It reached a number of results, the most important of which is that it has found that information system has led to a significant increase in the efficiency of operations and activities of the human resource management $(\mathrm{HRM})$ and through the effective and efficient communication and participation of the employee, and it pointed out that the roles and skills of human resource managers have greatly expanded over the time by relying and developing of their knowledge continuously about the use of information system in the performance of their basic tasks.

* The study (Mishra \& Akman, 2013) pointed out the applications of (MIS) in the field of human resources management (HRM) in the organizations in the industrial and commercial sector in Turkey (the place of this study).

The study depended on the descriptive analytical approach using the questionnaire from (55) paragraphs distributed among 221 individuals, and making personal interview.

This study reached a number of results, the most important of them is that (MIS) and a wide range of its applications have had a major impact in developing human resource management (HRM), as well as it indicated that the impact of (MIS) on (HRM) has got the attention of academics for a long time, however, no experimental or applied research has been conducted in this field in Turkey. The study results also showed that (MIS) are used in human resource management tasks in various sectors by traditional grounds.

* the Study of (Munirat, 2016) has aimed to know the impact of (MIS) on the performance of companies in the private sector in the Nigerian capital by the effect of measuring the dimensions of (MIS) on the overall performance of these companies. Data was collected by personal interviews for (155) individuals from all administrative levels, and questionnaire 


\section{International Journal of Social Science and Economic Research}

ISSN: $2455-8834$

Volume:06, Issue:01 "January 2021"

with (33) items for a number of owners of small and intermediate projects in the Nigerian capital.

The study reached a number of results, the most important one is that there are many obstacles for the growth and development of (MIS) other than financial obstacles, including efficiency of performance for the information system, lack of skills and knowledge, and mismanagement of databases in most of the organizations (companies, the objectives of this study).

* The study of (Wee, and See, 2009) has indicated the role of rapid technological progress and the widespread use of the Internet in developing human resources in Korean civil society organizations. (144) questionnaires were distributed on (7) organizations working in this field to HR personnel at all administrative levels.

The study reached some results, the most important one is that it clarified the importance of human capital as a key factor for success in projects.

Also, it showed that in the confrontation of increasing global competition and rapid changes, organizations have become interested in reducing numbers in the manpower, and they focus on raising capabilities in their competencies to achieve more innovation to remain able to compete by showing interest in an increased commitment to their staff (the human resource).

\section{Comments on the previous studies:}

In this section we provide an overview of previous studies chronologically from the most recent to the oldest, this helped to enrich the theoretical framework of this study and to build its structure, as well as to present the results reached in this study.

- Some of the previous studies that relate to the impact and role of (MIS) focused on improving the performance of the management process and the policies of (HRM) in private sector organizations (for-profit), and it was observed a little interest in the governmental sector (non-profit) despite its importance. and we as researchers do not believe, as far we've learned, that there are specialized studies in the field of practicing human resource functions that reveal the role of (MIS) in performing the functions of human resources management by focusing on the following most important human resource management functions: ( recruitment / choosing, appointment / training / performance evaluation) and analyzing this role.

\section{Significance of the Study}

The significance of this study involves two types of values, which are theoretical and practical.

- The main contribution of this study to provide a methodological rule for the optimal use of the means of (MIS) in the functions of (HRM). 


\section{International Journal of Social Science and Economic Research}

ISSN: $2455-8834$

Volume:06, Issue:01 "January 2021"

- The main contribution to raise the level of cultural and educational awareness of the importance of switching to e-HRM, which is considered one of the most important electronic management systems.

- The main contribution to the integration of data and information between the various departments and sections within (HRM), as well as for the whole ministry in general, seeking to achieve the goals of the ministry and providing the necessary flexibility to respond to successive changes.

- Contributing to improve the performance of (HRM)'s in (MOCSI) in building an infrastructure base of information technologies aiming to improve the actual performance and practices of (HRM) and develop it into strategic practices for human resource that depend on information and knowledge dissemination, and thus it will be reflected in the efficiency and performance of the employees if these recommendations are taken into action.

- Emphasizing the importance of using (MIS) in all administrative functions of human resources, technical functions in particular, as well as affirming the positive effects on the performance in most functions of (HRM).

\section{The paper in the special issue}

The article in the special issue, the role of Management Information System (MIS) to Improve Functions of the Human Resources Management to contribute individually to the strategic Movement of their company and supporting HRM policies and practices. Taking strategic sensitivity, resource fluidity and collective commitment as the basis, the paper identifies specific individual behaviors, and analyze and review how skills, and practices driving these behaviors, and their supporting HRM practices affect the strength of each vector, and of the forces that provide energy in fostering strategic Movement. This provides a profile of skills and capabilities individuals need in order to best contribute to the strategic Movement of their organization and of HRM practices to put in place.

In order to augment strategic Ability. The paper formulates HRM domains of action that can improve effective improvisation and could also inform the practice the informed HRM. The paper also discusses the implications of HRM domains for HRM based strategic Movement,

The followed purpose to examines the relationship between key conceptual dimensions of entrepreneurial team and strategic Movement and explores the connections between these two literature streams. The paper suggests the potential value from a cross-fertilization approach and points out the future research directions through which these literature streams might be advanced collectively and effectively. The paper sheds some important light on the relationship between strategic Movement and HRM through the lens of managing effective entrepreneurial teams in differing contexts. 


\section{International Journal of Social Science and Economic Research}

ISSN: $2455-8834$

Volume:06, Issue:01 "January 2021"

Finally, this paper of the developed a conceptual model that integrates ability, motivation and opportunity enhancing human resource management (HRM) practices framework and transactive memory system.

\section{Suggestion}

The Suggestion of the papers are presented here. The paper highlights the skills and capabilities necessary to achieve strategic Movement and focuses on specific HR practices that fosters the skills and capabilities needed. This paper contributes by exploring individual level context of strategic Movement and specifying individual level behavior and skills needed to achieve strategic Movement.

The paper also has managerial implications since it provides a profile of skills and capabilities individuals need in order to best contribute to the strategic Movement.

The paper contributes by examining the country level context of strategic Movement. The paper indicates that SWFs have a profound implication for HR practice. For instance, local business and domestic government may put pressure to promote local economic environment and domestic government. Consequently, the investment strategy of SWFs would be profoundly influenced.

The paper proposes imp improvisational capabilities in order to augment strategic Movement. Thus, the paper has implications for organization intending to enhance strategic Movement. In this context, the paper formulates HRM domains of action that can improve effective improvisation and could also inform the practice of a paradox- informed HRM.

An understanding of the role of HRM within the strategic Movement is also important entrepreneurial firms. The paper examines the relationship between key conceptual dimensions of entrepreneurial team and strategic Movement.

The paper sheds some important light on the relationship between strategic Movement and Management Information System (MIS) with Improving Functions of HRM through the lens of managing effective entrepreneurial teams in differing contexts.

\section{Conclusion}

The novelty of this special issue lies in highlighting the Role of Management Information System (MIS) to Improve Functions of the Human Resources Management Movement practices. The papers in the special issue contribute to the literature on strategic Movement by identifying gaps in the existing yet fragmented prior research and consolidating existing theoretical concepts. It offers novel insights in terms of the implications of strategic Movement on the HR practices and suggests new venues for future research in strategic Movement.

\section{References}




\section{International Journal of Social Science and Economic Research}

ISSN: $2455-8834$

Volume:06, Issue:01 "January 2021"

Aaker, D., A., Kumar,V., and Day, G.,S.,(2012), Marketing Research,7th ed.,John Wiley and Son Inc. New York.

Adewoye J. O \& Kehinde,O., (2012), The Impact of Information Technology (IT) on Human Resource Management (HRM):An Empirical evidence from Nigeria Banking Sector. European Journal of Business and Management. Vol. 4, No.6. www.iiste.org.

Almasri, R., \& Navathe, S.,B., (2011),Fundamentals of Data Base system, Pear soon , Education., Irwin: McGraw-Hill Companies, Inc. Boston.

Alter, S., (2012) ,Information Systems: The Foundation of E-Business, 6th ed., Prentice-Hall, Person Education, Upper Saddle River, New Jersey.

Anthony, P. \&, Kacmar, K.,m.,(2014), Human Resource Management: A strategic Approach, New York: The Dryden Press.

Armstrong, M., (2013) Handbook of Human Resource Management Practice, 10th ed., London: Kogan.

Chadee, C., \& Billy,p., (2014),Information Technology Strategy and Performance in Business ,Department of International Business, The University of Auckland, New York.

Charles T., \&, Mahithorn B., (2010), The Design of a Training Program Measurement Model, Journal of European Industrial Training, Vol, 26 Issue.

Khan \& Awan(2017)The impact of Management Information System (MIS) of the organization (Profitability, Innovation, and Growth), Journal of Poverty, Investment and Development.

Munirat, Y., Sanni, M., \&Kazeem, A. O. (2014). The Impact of Management Information System (MIS) on the Performance of Business Organization in Nigeria. International Journal of Humanities Social Sciences and Education (IJHSSE), 1

Laudon, K. C., \& Laudon, J. P. (2016). Management Information Systems: Managing The Digital Firm (14th ed.). New Jersey: Pearson Education.

O’Brien.J.,A.,(2007), Management Information Systems: Managing Information Technology in the E-Business Enterprise. 6th Ed., Irwin: McGraw-Hill Companies, Inc. , Boston.

Oz,\& Effy, (2009), Management Information System, Thomson, course Technology , 6th ed. New York.

Yassin ,Ait (2014). The Impact of Management Information System (MIS) on Management Decision Taking Erbed Municipality. Balga, University ,Jordon. 